\title{
An Investigation of the Present Living Condition of the Sericulturist Group in the Sericultural Area along the Jialing River Basin
}

\author{
Yijing Li, Hong Tao* \\ School of Journalism and Communication, Southwest University, Chongqing, China \\ Email: liyijing0515@163.com, , goodth@126.com
}

Received 27 June 2014; revised 27 July 2014; accepted 5 August 2014

Copyright (C) 2014 by authors and Scientific Research Publishing Inc.

This work is licensed under the Creative Commons Attribution International License (CC BY). http://creativecommons.org/licenses/by/4.0/

\section{(c) (i) Open Access}

\begin{abstract}
The Jialing River Basin sericultural area is an ancient mulberry growing and silkworm rearing area in China. In the period of Tang Dynasty and Song Dynasty, a lot of famous silk products were produced in this sericultural area. Until now, cocoon and silk are still the major source of revenue for local people, with sericulturists being the major group of people who grow mulberry and rear silkworms. This paper has adopted the method of field research and questionnaire survey to investigate the modern sericulturists in terms of ages, education level, acquisition of silkworm rearing skills, and the support of national policies etc., aiming to explore the reason why sericulture, as part of Chinese culture, can continue.
\end{abstract}

\section{Keywords}

Jialing River Basin Sericultural Area, Sericulturists, Interview, Questionnaire

\section{Introduction of the Sericultural Area along the Jialing River Basin}

There are five major sericultural areas in history, including the arid northern sericultural area, the Huang-Huai River basin sericultural area, the Yangtze River basin sericultural area, the central southern hilly region red-soil sericultural area and the sericultural area in the plain and hilly areas of southern China, among which the Jialing River basin sericultural area belongs to that of the Yangtze River basin. Cocoon and silk are the pillars of local economy, and the farmer groups in the area are called sericulturists.

*Corresponding author.

How to cite this paper: Li, Y. J., \& Tao, H. (2014). An Investigation of the Present Living Condition of the Sericulturist Group in the Sericultural Area along the Jialing River Basin. Advances in Applied Sociology, 4, 197-203.

http://dx.doi.org/10.4236/aasoci.2014.48024 
From the geographic perspective, Jialing River Basin sericultural area refers to the mulberry sericulture region ranging from Guangyuan in the upstream to Beibei in the downstream (National Sericultural Compartment Cooperative Group, 1986). Jialing River flows along the Sichuan Province and Chongqing, including the main towns like Guangyuan, Cangxi, Langzhong, Nanbu, Pengan, Nanchong, Wusheng, Hechuan and Beibei. Cocoon and silk are the local economic pillars of Santai and Shehong, by which the tributary Jialing River flows, while Langzhong, Nanchong and Hechuan are sales hubs of cocoon and silk.

There has been 3000 years of history for mulberry planting and silkworm rearing in Jialing River basin sericultural area, as Records of Huayang: Records of Ba XI says,

Dianjiang River, inland waters in northwestern county, is two hundred thousand meters long, where there

are silkworms, mulberry, cows and horses (Ren, 1987).

During the Qin and Han periods, silk industry was the major industry of Nanchong region. The government distributed $20 \mathrm{mu}$ (a unit of area $=0.0667$ hectares) of Yongye field (land which could be inherited) to encourage the cultivation of family mulberry fields, aiming at stably developing the production of silkworm and mulberry.

In the $6^{\text {th }}$ century during the Tang Dynasty and Song Dynasty, the development of silk industry in Langzhou and Nanchong reached its peak, with ghatpot, loessal, silk, deer fetus, quilt, satin and so on designated as imperial tributes. Nanchong was thus called "Millennium City of Silk", and there went a saying as "the quality of the silk of Nanchong competes that of Suzhou and Hangzhou and it is regarded as treasures". The silk was transmitted from Chang'an to Japan (The Record of Nanchong Silk Compilation Committee, 1991).

In 1920s to 1930s, Mr. Yin Liangyin was in charge of the silkworm industry of Sichuan Province, during this period he promoted the improvement of sericulture in Jialing River Basin. In 1929, the domestic export collection of raw silk reached 8970 dollars, and that of silk reached 12,170 dollars, setting the highest record in history, in which the sericulturists in Jialing River Basin had played an important role (Wang, 1995).

Nowadays the sericulturists in Jialing River Basin still rear silkworms and grow mulberry, but how is their life like today? What factors are affecting their life today?

We interviewed the sericulturists and the managers of the sericulture industry in this sericultural area, which is located in the Jialing River Basin.

\section{Research Methodology}

Interview: the subjects of interview were mainly composed of the sericulturists and the silkworm and mulberry sellers from Langzhong, Nanbu, Nanchong, Hechuan and Beibei.

Sericulturists: sericulturists from Xiaoyan Village in Nanbu and the Taihe-shiya Village in Hechuan.

Sellers: senior executives of LU SHEN GROUP, the deputy town chief and three village heads of Jianxing Town in Nanbu.

Xiaoyan Village is located by the Yuwu Highway in Nanbu County with 100 households. The sericulturists there rear silkworms three seasons a year, namely spring silkworm, autumn silkworm and late autumn silkworm. We interviewed a couple at their 50s, an old man at his 80s and a 2-year-old child. There were 120 dustpans in the cocoonery, which was very clean and tidy. The couple constantly removed the slag from the dustpan and added mulberry leaves into them. Many villagers were not at home with their houses locked at the village, some of whose doorframes were even skew. As for the silkworm cocoon selling, there are private businessmen coming over by vehicles along the highway by the village to buy the silkworm cocoon, at a price almost the same as that of the state-owned cocoon stands. Villagers do not have to travel a long way and wait in a line to sell their cocoons, and they can get paid in cash right after the cocoon weighing. The sericulturists enjoy a lot of freedom in the slack season, and all they have to do is to take care of the kids for their sons and daughters who have gone out for work. They can get 1000 yuan or more a year from their sons and daughters for raising the children.

Taihe-shiya Village in Hechuan is about 20 miles away from the urban area of Hechuan, with a population of 1600 people, among which 500 stay at home and the number of those at their 30s-40s is less than 20. There we interviewed the village secretary Zhou Meiyin, his wife and some sericulturists. Zhou is at his 50s, wearing a yellow sweater with many holes and a stubble of untrimmed beard that day. His house is a worn-out strip-style bungalow, whose left aisle is used for rearing silkworm. A sheet of silkworms can be sold at a price of 700 yuan on average. A couple in their prime of life can rear over ten sheets of silkworms a year, which can bring them an income of more than ten thousand. If they raise some pigs, chickens and rabbits and so on, they can live a very 
good life. The whole village rear altogether 80 sheets of silkworms in 2002, and 500 in 2005.

By implementing the policy of the converting farmland into forest, the government subsidizes the mulberry field for 245 yuan per mu. The hilly area can grow mulberry and is good for silkworm rearing. But due to the disease, the villagers will not rear a large number of silkworms. A retired worker from Chengdu bought $50 \mathrm{mu}$ of farmland in Taihe-shiya Village to grow mulberry and rear silkworms. He hired the villagers to help. He can earn about 300,000 yuan a year for rearing hundreds of sheets of silkworms, but he is faced with the silkworm disease risk.

We interviewed the senior executives of LUSHEN GROUP, which is founded in Nanbu in 2002, taking charge of integrated management of mulberry, silkworm, cocoon, silk and silk fabric. It owns 30 silkworm and mulberry production bases with 12 automatic silk reeling machines, making it the biggest reeling silk enterprise in Nanchong. The senior executives of LUSHEN GROUP all graduate as sericultural majors from famous inland agricultural universities, some of who used to study in Japan. LUSHEN GROUP is staffed by graduates from the Southwest Agriculture University, the Sichuan Sericulture Research Institution, Sichuan University and Zhejiang University and so on, with an objective of constructing Nanbu into the best superior quality sericulture production base in Sichuan Province and first rank throughout the country and a green, ecological and environmentally-friendly silk industrial base for foreign exchange. Up to 2004, the quality of raw silk produced by the company has reached at $4 \mathrm{~A}$ or $5 \mathrm{~A}$ level, some even at $6 \mathrm{~A}$ level, realizing a sales revenue of 110 million yuan and a foreign exchange of 4.75 million yuan.

Zhao Lin, the deputy town chief of Jianxing Town in Nanbu, is in charge of the sericulture work. As a young man newly graduating from the Law Department of West China University, he is faced with pressure from both work and life. One thing upsets him is that the workload is heavy while the labor force is insufficient. The implementation work of the government's policy of transferring the mulberry from the east to the west is a great difficulty for him due to the lack of labor force. The second worrisome thing is that he cannot make both ends meet with a low salary. Zhao Lin gets a salary plus subsidies of only 1100 yuan a month, of which he has to spend about 200 yuan on telephone and some other on daily necessities and social engagements. The house price in urban Nanbu is no less than 1400 yuan $/ \mathrm{m}^{2}$, which poses great pressure on him, because he has no savings to buy a house, thus feeling sorry for his family.

The village heads are living a happy life. Zhao Bin is the head of the Third Village in Jianxing Town, Zhao Hanqing the Fourteenth Village, and Tu Yinghua the Ninth Village. They often assist the sericulture officer Zhao Changsu in town with his work. Each of them owns a motorbike and a cellphone, making it very convenient for them to contact with each other. Among them Zhao Hanqing and Zhao Bin are only at their 30s. Every day they shuttle between Jianxingchang, where the town government is located, and their home at the village by motorbike, and it takes them only 20 minutes or so one way. The village heads have established the Sericulture Cooperative of Longfeng Village, which is a self-service non-governmental organization located at the Shimen Hall of the Third Village, mainly in charge of ordering silkworm eggs, distributing silkworm medicine and purchasing fresh cocoon. They rent a set of rooms in Jianxing Town in the name of the Cooperative, where they can gather there to have lunch, drink tea, play cards, wash hair and sing after the meeting in town is over.

\section{Questionnaires Survey}

We chose to distribute our questionnaires in Wanjia wan, Wuxin village, which is a famous sericultural area in Beibei District, Chongqing.

Questions are designed according to five dimensions: first, the survey of the educational level of the sericulturists; second, the survey of the national sericultural policy' influence on the sericulturists; third, the survey of the influence of the mulberry plantation and silkworm raising on the sericulturists' household income; fourth, the survey of traditional sericulture culture's influence on modern sericulturist; fifth, the survey of the age of the sericulturists' family members that stay at home all the year round. There are five options for each question and 4 - 7 questions for each dimension.

The design flow of the questionnaire was divided in five steps:

Firstly, extract the essential factors from the case investigations in the main sericultural areas along the Jialing River Basin;

Secondly, form dimensions for our survey after extracting essential factors, design questionnaires according to five level and do test survey in Wanjia wan; 
Thirdly, revise the previous questionnaires and form the formal ones;

Fourthly, 90 formal questionnaires were distributed and 58 effective ones were recalled.

In addition, three sericulturists were trained to help others finish the questionnaires.

\section{Results and Discussion}

First, the education level among modern rural sericulturist is not optimistic. In Table 1, 70.7\% have been educated in primary school and the rest of them have only been educated in middle school. Though living in the countryside, the sericulturists actually play a major part in the operation of sericulture since the cocoon produced by them has become a standard commodity. However, they do not process the necessary knowledge and skills, thus making them disadvantaged groups in sericulture industry.

Secondly, technology comes first for modern sericulturists. They take sericulture skills training for at least one week and at most three weeks per year, in addition, in Table 1,32\% of them have some contact with the technicians during sericultural season, while $36.2 \%$ of them have little contact. With regard to ordering sheets for sericulture, rearing of young silkworm, the purchase and distribution of disinfectants, silkworm disease prevention, they hope to get support from technicians, which shows their admiration for sericultural technology.

Thirdly, since national and local efforts to popularize sericultural development and implementation of policies are not enough, it is difficult for the silkworm farmers to benefit from the policy. And national and local policies are hard to fulfill.

Fourthly, sericulture income and household expenditure can not reach a balance. In Table 1, only $3.4 \%$ of the households can earn over 20,000 RMB and $62.1 \%$ of them can only earn $5000-10,000$, relying on other ways to maintain the family expenses.

Fifthly, some elements of traditional sericulture culture, such as taboos before sericulture or prayers and ritual activities before and after the sericulture have almost disappeared. In Table 1, only $6.9 \%$ of the sericulturists in

Table 1. Influences on the sericulturist group in terms of educational level, national policies, sericultural income and traditional sacrificial practices.

\begin{tabular}{|c|c|c|c|c|c|}
\hline Item & Valid & $\begin{array}{l}\text { Frequency } \\
\text { (\%) }\end{array}$ & $\begin{array}{l}\text { Percent } \\
(\%)\end{array}$ & $\begin{array}{l}\text { Valid percent } \\
\text { (\%) }\end{array}$ & $\begin{array}{c}\text { Cumulative percent } \\
\text { (\%) }\end{array}$ \\
\hline \multirow{2}{*}{$\begin{array}{l}\text { How many years have you been educated in } \\
\text { school? }\end{array}$} & 4 & 17 & 29.3 & 29.3 & 29.3 \\
\hline & 5 & 41 & 70.7 & 70.7 & 100 \\
\hline \multirow{3}{*}{$\begin{array}{l}\text { How many years of the silkworm-specified } \\
\text { school education have you had? }\end{array}$} & 4 & 10 & 17.2 & 17.2 & 17 \\
\hline & 5 & 48 & 82.8 & 82.8 & 100 \\
\hline & 3 & 19 & 32.8 & 32.8 & 32.8 \\
\hline \multirow[t]{3}{*}{$\begin{array}{l}\text { How is your connection with the sericultural } \\
\text { technicians? }\end{array}$} & 4 & 18 & 31 & 31 & 63.8 \\
\hline & 5 & 21 & 36.2 & 36.2 & 100 \\
\hline & 3 & 2 & 3.4 & 3.4 & 3.4 \\
\hline \multirow{4}{*}{$\begin{array}{l}\text { Do you know the policy of transferring the } \\
\text { mulberry from the East to the West? }\end{array}$} & 4 & 29 & 50 & 50 & 53.4 \\
\hline & 5 & 27 & 46.6 & 46.6 & 100 \\
\hline & 1 & 2 & 3.4 & 3.4 & 3.4 \\
\hline & 2 & 2 & 3.4 & 3.4 & 6.9 \\
\hline \multirow[t]{4}{*}{$\begin{array}{l}\text { How much is your annual income by raising } \\
\text { silkworm? }\end{array}$} & 3 & 10 & 17.2 & 17.2 & 24.1 \\
\hline & 4 & 36 & 62.1 & 62.1 & 86.2 \\
\hline & 5 & 8 & 13.8 & 13.8 & 100 \\
\hline & 2 & 1 & 1.7 & 1.7 & 1.7 \\
\hline \multirow{4}{*}{$\begin{array}{l}\text { Are there any sacrificial practices after detaching } \\
\text { cocoon in your village? }\end{array}$} & 3 & 1 & 1.7 & 1.7 & 3.4 \\
\hline & 4 & 4 & 6.9 & 6.9 & 10.3 \\
\hline & 5 & 52 & 89.7 & 89.7 & 100 \\
\hline & Total & 58 & 100 & 100 & \\
\hline
\end{tabular}


the village keep a tradition of performing ritual activities.

Sixthly, most of the sericulturists are above 45 years old, among which many are over 55. And those who are under the age of 44 are not easy to find.

However, the country is still the incubator of traditional culture. The sericulturists are a solid and simple grassroots social organization which consist of the village heads, the elderly families, nuclear families, clan relationships and the like. We believe that after entering the industrial society, sericulture is no longer one of the most important elements, but it still exists and the sericulturist group make up the main part of sericultural society. Villages are the incubators of traditional culture which can save material matters and change them into spiritual ones through purification for a long time. And that is why the inheritage of traditional culture can continue.

\section{Conclusions}

Farming and sericulture is the root of the Chinese agricultural society. From the Tang Dynasty to the late Qing Dynasty, silk was always an important economic source of rural households and the country. Today, China still has a predominantly agricultural population; therefore, planting mulberry and sericulture still is one of the main channels of silkworm raisers' family income. However, the country is still the incubator of traditional culture. The sericulturists are a solid and simple grassroots social organization which consists of the village heads, the elderly families, nuclear families, clan relationships and the like. We believe that after entering the industrial society, sericulture is no longer one of the most important elements, but it still exists and the sericulturist group makes up the main part of sericultural society. Villages are the incubators of traditional culture which can save material matters and change them into spiritual ones through purification for a long time. And that is why the inheritage of traditional culture can continue.

Our investigation of the present living condition of the sericulturist group in the sericultural area along the Jialing River Basin, is to discover the continued parts and the change parts of Chinese traditional culture.

\section{Acknowledgements}

Major Commission of Chongqing Social Science Research Project Class B. project number: 20122DB11, "Research of the Transmission System of Modern Agricultural Technique”.

The Fundamental Research Funds of Southwest University, project number: SWU 1409239. "Research of Modern Agricultural Culture Transmission in Chongqing”.

\section{References}

National Sericultural Compartment Cooperative Group (1986). China's Sericultural Compartment. Sichuan: Sichuan Science and Technology Press.

Ren, N. Q. (1987). The Correcting and Compiling Legend of Chronicles of Huayang. Shanghai: Shanghai Ancient Books Publishing House.

The Record of Nanchong Silk Compilation Committee (1991). The Record of Nanchong Silk. Beijing: China Economic Press.

Wang, Z. M. (1995). The History of the Silk of the Republic of China. Beijing: China Textile Press. 


\section{Appendix}

\section{Standard Questionnaire: The Survey on the Social Function of Education in Silk Cultural Heritage}

Dear ladies and gentlemen,

Thank you for your support for this survey! The questionnaire was designed to know education's impact on your family or you with regard to politics, economy, culture in the process of silk culture heritage along the Jialing River Basin. I hope that through the investigation, we can have an accurate grasp and understanding of sericultural families and then provide support for your families or community. Please read each sentence carefully and answer according to follow your own actual situation. Mark a tick $(\sqrt{ })$ on the option which suits you. Be careful not to omit any question and pay attention to not to mix the question numbers. This survey is used only for scientific research, we will keep your privacy, please do not have any concerns.

\section{Part One: The Survey of the Educational Level of the Sericulturists}

A01. How many years have you been educated in school?
1. more than 16 years
2. 13 - 15 years
3. 10 - 12 years
4. 5 - 9 years
5. 0 - 4 years

A02. How many years of the silkworm-specified school education have you had?
1. 4 years
2. 3 years
3. 2 years
4. 1 year
5. None

A03. How many weeks do you take skill training on silkworm per year?
1. more than 3 weeks
2. 2 weeks
3. 1 week
4. less than 1 week
5. none

A04. To what extent can you skillfully use the computer to acquire information on silkworm?
1. quite skilled
2. skilled
3. know the basic manipulation
4. can do simple manipulation
5. never

A05. How is your connection with the sericultural technicians?
1. quite intimate
2. intimate
3. have some connection
4. have little connection
5. have no connection

Part Two: The Survey of the National Sericultural Policy's Influence on the Sericulturists B01. Do you know the policy of transferring the mulberry from the East to the West?
1. know very well
2. know well
3. generally know
4. know little
5. do not know
B02. Do you know the project of double millions?
1 . know very well
2. know well
3. generally know
4. know little
5. do not know

B03. Do you know the silkworm industry planning by the Chongqing eleventh five-year plan?
1 . know very well
2. know well
3. generally know
4. know little
5. do not know

B04. Have you increased the sheets of raising silkworm in your house due to the advocation of the government?
1. have increased in a large scale
2. have increased a lot
3. have increased some

4. have not increased

5. have decreased

B05. Have you increased the acres of your mulberry field due to the advocation of the government?
1. have increased in a large scale
2. have increased a lot
3. have increased some
4. have not increased
5. have decreased

Part Three: The Survey of the Influence of the Mulberry Plantation and Silkworm Raising on the Sericulturists' Household Income

C01. How much is your annual income by raising silkworm?
1. More than 20 thousands
2. 15 thousands to 20 thousands
3. 10 thousands to 15 thousands

4. 5 thousands to 10 thousands 5 . less than 5 thousands

C02.Can the income of raising silkworm cover your family expenses?
1. yes, a lot saved
2. yes, a little saved
3. yes, just enough 
4. not enough

5. far from enough

C03. How much proportion does the annual income take by raising silkworm compared with the total annual income of your family?

1. more than 50 percent

4. a little

2. 50 percent

5. almost none

3. less than 50 percent

C04. How much money can be sent back from the migrant workers in your family?
1. more than 3 thousand
2. more than 2 thousand
3. more than 1 thousand
4. less than 1 thousand
5. none

Part Four: The Survey of Traditional Sericulture Culture's Influence on Modern Sericulturist D01. Are there any activities that are forbidden before raising silkworms?
1. a lot
2. many
3. some
4. rare
5. none

D02. Are there any autonomous silk reeling or weave pongee in your family?
1. a lot
2. many
3. some
4. rare
5. none

D03. Do you visit each other among neighborhood during the sericultural seasons?
1. very often
2. often
3. sometimes
4. rarely
5 . never

D04. Are there any worship ceremonies after detaching the cocoon?
1. a lot
2. many
3. some
4. rare
5. none

D05. Do you know "Leizu”, the silkworm goddess?
1. know very well
2. know well
3. generally know
4. know little
5. do not know
D06. Are
1. a lot
2. many
4. rare
5. none
3. some

Part Five: The Survey of the Age of the Sericulturists' Family Members That Stay at Home All the Year Round

E01. How many persons in your family are staying at home all the year round?
1. 5 persons
2. 4 persons
3. 3 persons
4. 2 persons
5. 1 person

E02. How many persons in your family are silkworm raisers?
1. 5 persons
2. 4 persons
3. 3 persons
4. 2 persons
5. 1 person

E03. How old are the silkw
1. older than 55 years old

4. 40 - 44 years old

$\mathrm{m}$ raisers in your family? (multiple choices)

E04. How many persons in your family are studying at school?
1. 4 persons
2. 3 persons
4. 1 person
5. none
3. 2 persons

2. 50 - 54 years old

3. 45 - 49 years old

E05. How old are the family members that are studying at school? (multiple choices)
1. older than 14 years old
2. older than 12 years old
3. older than 10 years old
4. older than 8 years old
5. younger than 7 years old

E06. How many persons in your family are not silkworm raisers?
1. 5 persons
2. 4 persons
3. 3 persons
4. 2 persons
5. 1 person

E07. How old are the family members that are not silkworm raisers?
1. older than 55 years old
2. 50 - 54 years old
4. 40 - 44 years old
5 . younger than 40 years old
3. 45 - 49 years old

Thanks very much for your cooperation! 
Scientific Research Publishing (SCIRP) is one of the largest Open Access journal publishers. It is currently publishing more than 200 open access, online, peer-reviewed journals covering a wide range of academic disciplines. SCIRP serves the worldwide academic communities and contributes to the progress and application of science with its publication.

Other selected journals from SCIRP are listed as below. Submit your manuscript to us via either submit@scirp.org or Online Submission Portal.
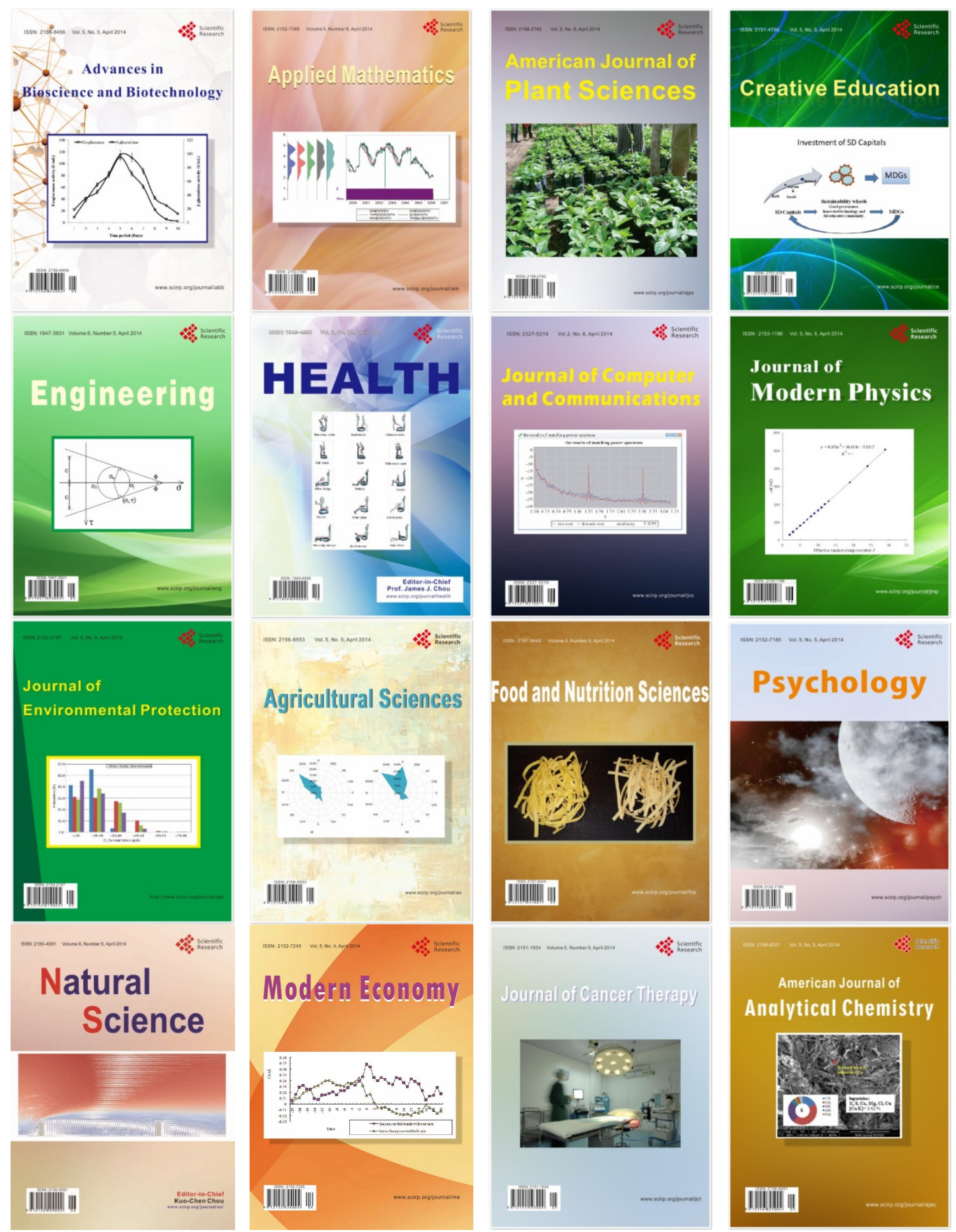